\title{
CAN AFFINITY INTERACTIONS INFLUENCE THE PARTITIONING OF GLUCOSE-6-PHOSPHATE DEHYDROGENASE IN TWO-PHASE AQUEOUS MICELLAR SYSTEMS?
}

\author{
André M. Lopes* and Adalberto Pessoa-Jr. \\ Departamento de Tecnologia Bioquímico-Farmacêutica, Faculdade de Ciências Farmacêuticas, Universidade de São Paulo, \\ 05508-900 São Paulo - SP, Brasil \\ Carlota de O. Rangel-Yagui \\ Departamento de Farmácia, Faculdade de Ciências Farmacêuticas, Universidade de São Paulo, 05508-900 São Paulo - SP, \\ Brasil
}

Recebido em 8/2/07; aceito em 27/11/07; publicado na web em 8/7/08

\begin{abstract}
In this work, we provide an investigation of the role and strength of affinity interactions on the partitioning of the glucose-6-phosphate dehydrogenase in aqueous two-phase micellar systems. These systems are constituted of micellar surfactant solutions and offer both hydrophobic and hydrophilic environments, providing selectivity to biomolecules. We studied G6PD partitioning in systems composed of the nonionic surfactants, separately, in the presence and absence of affinity ligands. We observed that G6PD partitions to the micelle-poor phase, owing to the strength of excluded-volume interactions in these systems that drive the protein to the micellepoor phase, where there is more free volume available.
\end{abstract}

Keywords: two-phase aqueous micellar systems; glucose-6-phosphate dehydrogenase; affinity partitioning.

\section{INTRODUCTION}

The industrial production of proteins and other biomolecules depends significantly on the extraction/purification processes. The development of techniques and methods for separation and purification of proteins has been essential for many of the recent advances in biotechnology. ${ }^{1}$ One of the techniques that can be considered promising is liquid-liquid extraction. In general, this method offers the possible advantages of versatility, scalability, cost effectiveness, and environmental friendliness compared to the conventional methods that they may replace.

In particular, two-phase aqueous micellar systems, formed by some surfactants at certain conditions, have been proposed as an attractive option, to be used in bioseparations. ${ }^{2-4}$ In these systems an aqueous surfactant solution, under the appropriate solution conditions, spontaneously separates into two predominantly aqueous, yet immiscible, liquid phases, one of which has a higher concentration of micelles than the other. ${ }^{4}$

An aqueous solution of the nonionic surfactant octylphenol ethoxylate (Triton X-114), for example, undergoes macroscopic phase separation upon increasing the temperature over a temperature known as the cloud-point of the surfactant, resulting in a bottom, micelle-rich phase and a top, micelle-poor phase, as represented in Figure 1.5,6 Since the concentration of surfactant in each phase exceeds its critical micelle concentration (CMC), a threshold concentration below which surfactant molecules are predominantly dispersed as monomers and above which they predominantly form micelles, micelles are present in both phases. ${ }^{3}$ However, the micelles in the concentrated phase (micelle-rich) usually are larger and more abundant than those in the diluted phase (micelle-poor). Two-phase aqueous Triton X-114 micellar system was first proposed for isolation of membrane proteins by Bordier. This author showed that hydrophilic proteins partition preferentially into the micellepoor phase, while hydrophobic or integral membrane proteins

*e-mail: andreml@usp.br

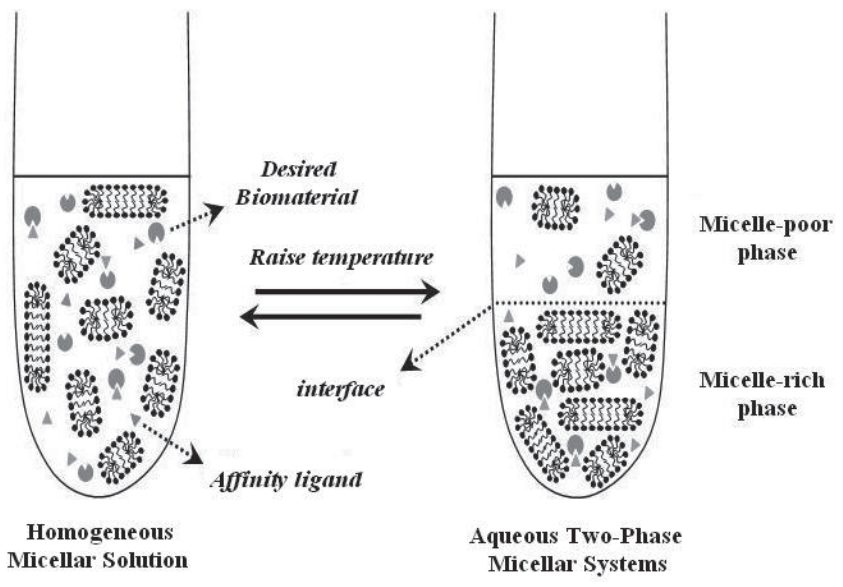

Figure 1. Schematic representation of a micellar system composed of surfactant, affinity ligands, and the desired biomaterial. Upon phaseseparation, the desired biomaterial can be concentrated in the micelle-rich phase according to affinity interactions, thereby enhancing the separation efficiency

partition preferentially into the micelle-rich phase. ${ }^{7}$

The potential of separating hydrophilic biomolecules in twophase aqueous micellar systems based on size differences was first recognized by Blankschtein and co-workers, who studied the partitioning of several water soluble proteins in the two-phase aqueous micellar system formed by the nonionic surfactant $\mathrm{C}_{10} \mathrm{E}_{4}$ (n-decyl tetra(ethylene oxide)). ${ }^{3,8,9}$ In addition, a theoretical description was developed to model the partitioning behavior of hydrophilic proteins in two-phase aqueous nonionic micellar systems based on statistical thermodynamics. ${ }^{8}$ According to this theory, the partitioning of proteins is governed primarily by repulsive, steric, excluded-volume interactions between the globular hydrophilic proteins and the non-charged cylindrical micelles, which drive the proteins preferentially to the micelle-poor phase. 
Therefore, under conditions of low protein concentration, noncharged surfactants, and low salt concentration, the partition coefficient is given by: ${ }^{8,10}$

$$
K_{p}^{E V}=\exp \left[-\left(\phi_{c}-\phi_{d}\right)\left(1+\frac{R_{p}}{R_{\circ}}\right)^{2}\right]
$$

where $K_{p}^{E V}$ is the partition coefficient of the protein based on excluded-volume interactions, $\phi_{c}$ and $\phi_{d}$ are the surfactant volume fractions in the concentrated and diluted phases, respectively, $R_{p}$ is the hydrodynamic radius of the protein, and $R_{o}$ is the cross-sectional radius of each cylindrical micelle. More recently, this theoretical description was extended to model the partitioning of hydrophilic proteins in two-phase aqueous mixed (nonionic/ionic) micellar systems, where electrostatic interactions between the charged mixed micelles and the charged proteins were accounted for. ${ }^{11,12}$

Affinity interactions have been suggested as a new playing force to improve the yield and the specificity of this type of process. ${ }^{3,13,14}$ A particularly attractive feature of these systems is the prospect of being able to select a target protein by preferentially extracting it into the micelle-rich phase, while simultaneously removing most of the impurities into the micelle-poor phase, owing to the excluded-volume interactions between these impurities and the micelles. ${ }^{15}$ Two-phase aqueous micellar systems may be a more convenient choice in affinity-enhanced extractions than their polymer counterparts, because the ligands might be incorporated in situ by micellar self-assembly, thus eliminating the need for time-consuming and expensive chemical synthesis. ${ }^{3}$ Usually, for two-phase aqueous polymer systems, the affinity ligand that targets the desired biomolecule is covalently attached to one of the phaseforming polymers through chemical synthesis, ${ }^{13,16-18}$ whereas in aqueous two-phase micellar systems, a relatively hydrophobic affinity ligand, specific for the desired hydrophilic protein, might strongly interact with it resulting in an affinity ligand-protein complex that could be concentrated in the micelle-rich phase, as represented in Figure 1. Nevertheless, there have been relatively few attempts to apply the concept of free affinity ligands to carry out bioseparations in two-phase aqueous micellar systems. ${ }^{19,20}$

The triazine dyes Cibacron Blue 3GA and Procion Red HE-3B have been studied as affinity ligands for the enzyme glucose-6phosphate dehydrogenase (G6PD) purification using chromatography. ${ }^{21,22}$ In this work, we present a discussion, based on experimental results, about the role of affinity interactions on the partitioning of the hydrophilic enzyme G6PD in two-phase aqueous micellar systems. The enzyme G6PD, presents great interest as analytical reagent, being used in various quantitative assays, including the measurement of creatin-kinase activity, hexoses concentrations, and as a marker for enzyme immunoassays. ${ }^{23,24}$

\section{EXPERIMENTAL}

\section{Materials}

The nonionic surfactant octylphenol ethoxylate (Triton X-114), the glucose-6-phosphate dehydrogenase enzyme from Leuconostoc mesenteroides, glucose-6-phosphate, $\beta$-nicotinamide adenine dinucleotide phosphate $\left(\beta-\mathrm{NADP}^{+}\right)$and the dyes cibacron blue $3 \mathrm{GA}$ and procion red HE-3B were all from Sigma (St. Louis, MO). The nonionic surfactant $n$-decyl tetraethylene oxide $\left(\mathrm{C}_{10} \mathrm{E}_{4}\right)$ was purchased from NIKKO Chemicals (Japan). All the solutions were prepared in McIlvaine's buffer, $\mathrm{pH} 7.2$, consisting of $16.4 \mathrm{mM}$ disodium phosphate and $1.82 \mathrm{mM}$ citric acid in water purified through a Millipore Milli-Q ion-exchange system (Bedford, MA). All the other reagents were of analytical grade. The glassware used was washed in a 50:50 ethanol: $1 \mathrm{M}$ sodium hydroxide bath, followed by a $1 \mathrm{M}$ nitric acid bath, rinsed copiously with Milli-Q water, and finally dried in an oven.

\section{Determination of G6PD and affinity ligands concentrations}

The determination of G6PD concentrations in aqueous surfactant solutions was based on a well-established enzymatic assay. ${ }^{25}$ The activity of G6PD was measured by determining the rate of NADPH formation, which absorbs ultraviolet light at $340 \mathrm{~nm}$, using a Beckman DU-640 (Fullerton, CA) spectrophotometer. To prevent phase separation during the assay, a temperature of $15{ }^{\circ} \mathrm{C}$ was employed. One G6PD unit was defined as the amount of enzyme that catalyzes the reduction of $1 \mu \mathrm{mol}$ of $\mathrm{NADP}^{+}$per minute under the assay conditions.

The concentrations of cibacron blue and procion red were determined spectrophotometrically, at their respectives $\lambda_{\text {MAX }}(\lambda=611$ and $515 \mathrm{~nm}$, respectively) in a Beckman DU-640 spectrophotometer, with the help of calibration curves.

\section{G6PD partitioning in two-phase aqueous micellar systems}

Buffered solutions, each with a total mass of $3 \mathrm{~g}$, were prepared in $10 \mathrm{~mL}$ graduated test tubes by the addition of the desired amounts of surfactant (TX-114 or $\mathrm{C}_{10} \mathrm{E}_{4}$ ), ligand (cibacron blue or procion red) and G6PD. Since the enzymatic assay for determination of G6PD concentrations is very sensitive, there was no need to use large amounts of the enzyme and, therefore, the overall G6PD concentration in each partitioning experiment was $0.007 \%(\mathrm{w} / \mathrm{w})$ $(0.7 \mathrm{mM})$. The systems were well mixed and equilibrated at $4{ }^{\circ} \mathrm{C}$ in order to form a clear and homogeneous single phase. Subsequently, the systems were placed in a thermo-regulated device, previously set at the desired temperature, and maintained there for $3 \mathrm{~h}$ to attain partitioning equilibrium. After that, the two coexisting micellar phases formed were withdrawn separately with great care, using syringe and needle sets, and the concentrations of G6PD and affinity ligands (cibacron blue or procion red) in each phase were determined. Each partitioning experiment was carried out in triplicate to verify reproducibility.

The partitioning behaviors of G6PD and affinity ligands in the two-phase aqueous micellar systems were quantified in terms of the partition coefficient, $K_{G G P D}$ or $K_{\text {Ligand }}$, defined as follows:

$K \equiv \frac{C_{C}}{C_{D}}$

where $C_{C}$ and $C_{D}$ are the G6PD or affinity ligand concentrations in the concentrated and diluted phases, respectively.

\section{Mapping the coexistence curves of the triton X-114/buffer and $\mathrm{C}_{10} \mathrm{E}_{4}$ /buffer systems}

The phase diagrams of the nonionic surfactants in buffer were obtained by the cloud-point method. ${ }^{8,26,27}$ Briefly, buffered surfactant solutions of known concentrations were prepared and placed in a transparent thermo-regulated device whit temperature control within $0.02{ }^{\circ} \mathrm{C}$. A magnetic stirrer was used to ensure temperature and concentration homogeneity. The temperature was first lowered such that the solution exhibited a single, clear phase. Then, the temperature was raised slowly, and the temperature at which the 
solution first became cloudy, indicating the onset of phase separation, was taken as $\mathrm{T}_{\text {CLOUD }}$. The procedure was repeated three times for each data point to ensure reproducibility. The Triton X114 and $\mathrm{C}_{10} \mathrm{E}_{4}$ concentrations in each coexisting phase of a twophase system can be read off the phase diagram by noting the intersections of the operating tie-line and the fitted coexistence curve (Figure 2).

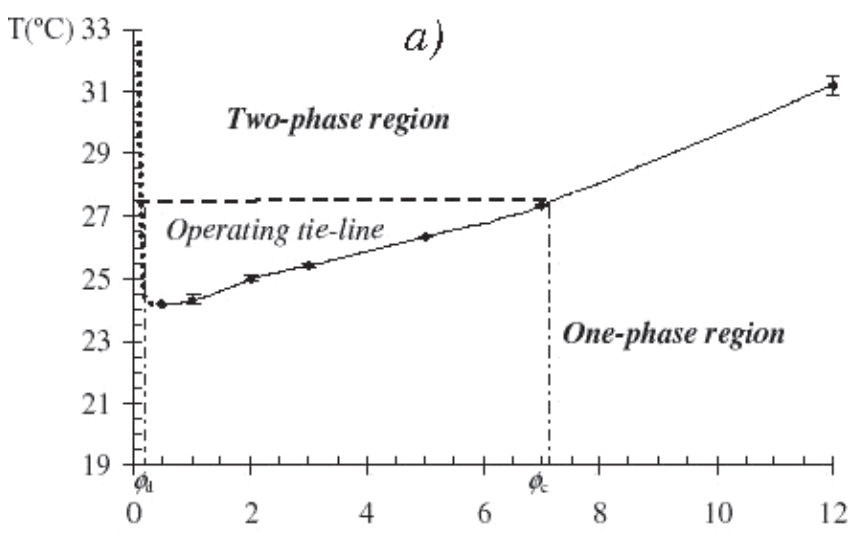

Concentration of Triton X-114 (\%w/w)

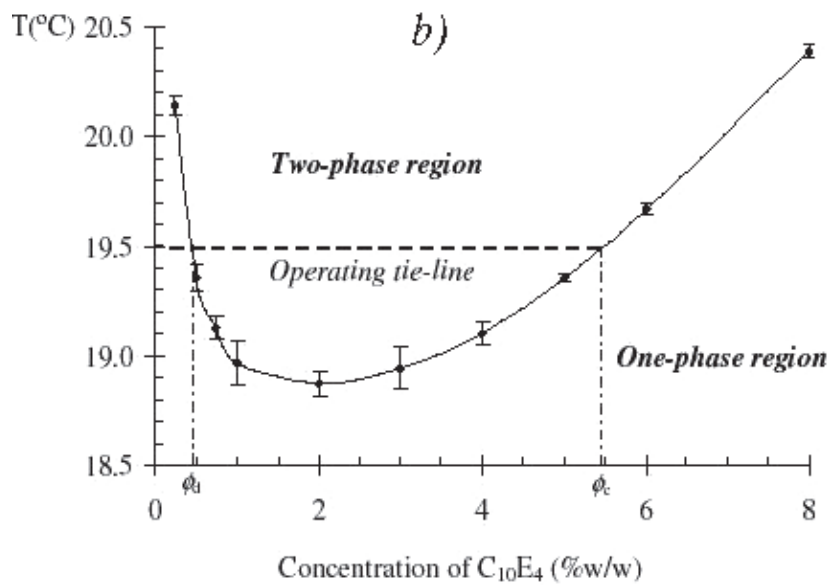

Figure 2. Experimentally determined coexistence curves of the TX-114 micellar system ( $\boldsymbol{a}$ ), and $C_{10} E_{4}$ micellar system (b), showing the corresponding tie-lines employed in the partitioning experiments. The two-phase region, the one-phase region, and the operating tie-lines are indicated. The error bars represent $95 \%$ confidence levels for the measurements

\section{RESULTS AND DISCUSSION}

\section{Coexistence curves of the aqueous micellar systems studied}

The coexistence curves obtained for TX-114 and $\mathrm{C}_{10} \mathrm{E}_{4}$ aqueous micellar system are presented in Figure 2. As can be seen, phase separation occurs upon increasing the temperature. The tie-lines corresponding to the partitioning conditions are also represented in Figure 2 and served as basis to calculate the excluded-volume effects $\left(\phi_{c}-\phi_{d}\right)$, by approximating volume fractions as mass fractions. The $\phi_{\mathrm{c}}$ and $\phi_{\mathrm{d}}$ are represented in each coexistence curve, and these values can be obtained since both phases have densities of approximately $1 \mathrm{~g} / \mathrm{mL}$, and therefore, weight fractions can be approximately as volume fractions. Therefore, the "excluded-volume effect" $(E V)$ was calculated with the help of the following equation:
$E V \equiv \frac{\left(\phi_{c}-\phi_{d}\right)}{100}$

Partitioning of the ligands in two-phase aqueous micellar systems

The partitioning of the ligands cibacron blue and procion red, was studied in Triton X-114 and $\mathrm{C}_{10} \mathrm{E}_{4}$ micellar systems, in the absence of G6PD. These dyes possess chemical structures that mimics the coenzyme NAD $(\mathrm{P})^{+}$and ATP molecule. ${ }^{28}$ According to Kroner et $a l .{ }^{29}$ the cibacron blue and procion red can be considered competitive inhibitors of G6PD. It is well-known that cibacron blue specifically interacts with a series of $\mathrm{NAD}^{+}$-dependent enzymes, including alcohol dehydrogenase, and is extensively employed as a bio-mimetic dyeaffinity ligand for separating these proteins in column chromatography or two-phase aqueous polymer system. ${ }^{30-32}$

The concentration of ligands was $0.005 \mathrm{mg} / \mathrm{g}\left(6.5 \times 10^{-3} \mathrm{mM}\right.$ of cibacron blue and $3.4 \times 10^{-3} \mathrm{mM}$ of procion red), since this amount was low enough to do not cause alterations in the coexistence curve and still high enough to allow spectrophotometric measurement of ligand concentration in the phases obtained. For Triton X-114, it was employed a surfactant concentration of $1.5 \%(\mathrm{w} / \mathrm{w})(35.15 \mathrm{mM})$ and the partitioning was carried out at $27.5^{\circ} \mathrm{C}$. For $\mathrm{C}_{10} \mathrm{E}_{4}$, the conditions were $2.5 \%(\mathrm{w} / \mathrm{w})(74.74 \mathrm{mM})$ of surfactant and $19.5^{\circ} \mathrm{C}$. Table 1 present the values of partition coefficients of cibacron blue and procion red ligands $\left(K_{\text {Ligand }}\right)$ in the TX-114 and $\mathrm{C}_{10} \mathrm{E}_{4}$ micellar systems, respectively. The activity balances closed in $100 \%$ within the experimental error.

Table 1. Experimentally measured partition coefficients $\left(K_{\text {ligand }}\right)$ of cibacron blue and procion red in the micellar systems studied. The error intervals represent $95 \%$ confidence level for the measurements

\begin{tabular}{lcccc}
\hline $\begin{array}{l}\text { Micellar } \\
\text { System }\end{array}$ & $T\left({ }^{\circ} \mathrm{C}\right)$ & $E V\left(\phi_{\mathrm{c}}-\phi_{\mathrm{d}}\right)$ & Ligand & $\mathrm{K}_{\text {ligand }}$ \\
\hline $\mathrm{TX}-114$ & 27.5 & 0.071 & $\begin{array}{c}\text { Cibacron blue } \\
\text { Procion red }\end{array}$ & $12.3 \pm 0.7$ \\
& & & Cibacron blue & $9.5 \pm 0.2$ \\
$\mathrm{C}_{10} \mathrm{E}_{4}$ & 19.5 & 0.050 & Procion red & $8.1 \pm 0.3$ \\
\hline
\end{tabular}

As can be seen from Table 1, both dyes partitioned preferentially to the concentrated, micelle-rich phase of a Triton X-114 system, resulting in partition coefficients higher than $1\left(K_{\text {cibacron blue }}=12.3\right.$ and $\left.K_{\text {procion red }}=11.5\right)$. Similar results were observed in the $\mathrm{C}_{10} \mathrm{E}_{4}$ system with $K_{\text {cibacron blue }}=9.5$ and $K_{\text {procion red }}=8.1$.

The behavior of triazine dyes in two-phase aqueous micellar systems reflects their chemical structures (Figure 3). The combination of hydrophobic groups with charged terminal portions confers an anphiphilic character to these molecules. Consequently, triazine dyes usually partition to the concentrate, micelle-rich phase, where there is more micelles to interact.

G6PD partitioning in the two-phase aqueous nonionic micellar systems in the presence and absence of affinity ligands

Partitioning of the G6PD enzyme was carried out in Triton X114 system, in the presence of the affinity ligands cibacron blue and procion red, separately. It was used the same conditions of the ligands partitioning experiment $(0.005 \mathrm{mg} / \mathrm{g}$ ligand, $1.5 \%(\mathrm{w} / \mathrm{w})$ of 
a)
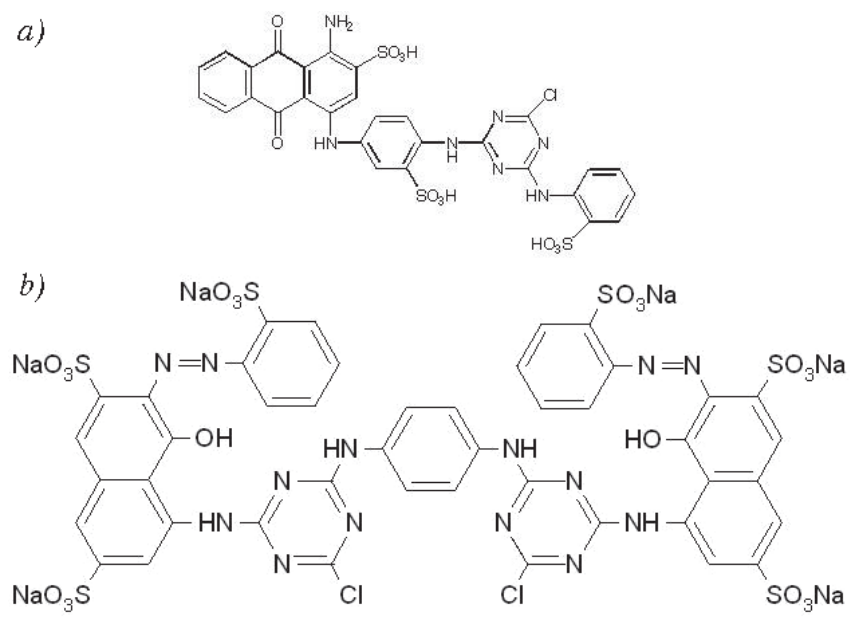

Figure 3. Chemical structures of the triazine dyes: Cibacron Blue $3 G A(a)$ and Procion Red HE-3B (b)

Triton X-114, and $\mathrm{T}=27.5{ }^{\circ} \mathrm{C}$. According to the stoichometry of the enzyme-ligand reaction, the two dyes were added in excess. An experiment of G6PD partitioning in Triton X-114 system in the absence of affinity ligands was also carried out to better evaluate the effect of affinity interactions on the enzyme partitioning behavior. The concentration of G6PD used does not interfere in the coexistence curve and, therefore, the excluded-volume effect was maintained constant by using the same partitioning conditions both in the presence and in the absence of affinity ligands, corresponding to a $\left(\phi_{\mathrm{c}}-\phi_{\mathrm{d}}\right)=0.071$. Table 2 presents the values of partition coefficient obtained for G6PD $\left(K_{\mathrm{G} 6 \mathrm{PD}}\right)$.

Table 2. Experimentally measured G6PD partition coefficients $\left(K_{G 6 P D}\right)$ in the micellar systems studied, in the absence and presence of the affinity ligands cibacron blue and procion red. The partition coefficients of the ligands $\left(K_{\text {ligand }}\right)$ for these experiments are also presented. The error intervals represent $95 \%$ confidence level for the measurements

\begin{tabular}{|c|c|c|c|c|c|}
\hline $\begin{array}{l}\text { Micellar } \\
\text { System }\end{array}$ & $\begin{array}{c}T \\
\left({ }^{o} \mathrm{C}\right)\end{array}$ & $\begin{array}{c}E V \\
\left(\phi_{\mathrm{c}}-\phi_{\mathrm{d}}\right)\end{array}$ & Ligand & $\mathrm{K}_{\mathrm{G} 6 \mathrm{PD}}$ & $\mathrm{K}_{\text {ligand }}$ \\
\hline TX-114 & 27.5 & 0.071 & $\begin{array}{c}\text { No ligand } \\
\text { Cibacron blue } \\
\text { Procion red }\end{array}$ & $\begin{array}{l}0.38 \pm 0.06 \\
0.45 \pm 0.05 \\
0.43 \pm 0.05\end{array}$ & $\begin{array}{c}- \\
11.8 \pm 2.1 \\
11.4 \pm 1.1\end{array}$ \\
\hline $\mathrm{C}_{10} \mathrm{E}_{4}$ & 19.5 & 0.050 & $\begin{array}{c}\text { No ligand } \\
\text { Cibacron blue } \\
\text { Procion red }\end{array}$ & $\begin{array}{l}0.44 \pm 0.02 \\
0.47 \pm 0.09 \\
0.49 \pm 0.04\end{array}$ & $\begin{array}{c}- \\
8.5 \pm 0.6 \\
6.1 \pm 1.0\end{array}$ \\
\hline $\mathrm{C}_{10} \mathrm{E}_{4}$ & 19.1 & 0.032 & $\begin{array}{c}\text { No ligand } \\
\text { Cibacron blue } \\
\text { Procion red }\end{array}$ & $\begin{array}{l}0.63 \pm 0.04 \\
0.72 \pm 0.04 \\
0.72 \pm 0.03\end{array}$ & $\begin{array}{c}- \\
3.7 \pm 0.5 \\
3.8 \pm 0.7\end{array}$ \\
\hline
\end{tabular}

According to Table 2, the $K_{\mathrm{G} 6 \mathrm{PD}}$ obtained in the presence of the affinity ligands and in the absence did not present statistically significant difference. The values of $K_{\mathrm{G} 6 \mathrm{PD}}$ in the absence of ligand, in the presence of cibacron blue, and in the presence of procion red were $0.38,0.45$ and 0.43 , respectively. These results might be a consequence of the high density of micelles in the micellar-rich phase, which generates an exclusion of the enzyme by the lack of volume in this phase. This hypothesis will be better discussed following in the text. The G6PD activity balances for these experiments, as well as for all the others carried out, closed in approximately $100 \%$, within the experimental error

The partition coefficient of the affinity ligands were also determined and did not present significant differences in comparison to ligand partitioning in the absence of G6PD, as can be seen from Table 2.

A partitioning study similar to the one in TX-114 micellar system was carried out in the micellar system composed of the surfactant $\mathrm{C}_{10} \mathrm{E}_{4}$. In this case it was employed surfactant concentration of $2.5 \%(\mathrm{w} / \mathrm{w})$ and temperature of $19.5{ }^{\circ} \mathrm{C}$, corresponding to $\left(\phi_{\mathrm{c}}-\phi_{\mathrm{d}}\right)=0.05$.

Table 2 presents the results of $K_{\mathrm{G} 6 \mathrm{PD}}$ obtained in the $\mathrm{C}_{10} \mathrm{E}_{4}$ micellar system in the presence and absence of the studied ligands. As can be seen, no significant differences were observed in the partitioning behavior of G6PD. The $K_{\mathrm{G} 6 \mathrm{PD}}$ values with no ligand and in the presence of cibacron blue and procion red were 0.44 , 0.47 , and 0.49 , respectively.

According to these results, the affinity interactions were not strong enough to influence G6PD partitioning at the conditions employed. A probable explanation for the small influence of the affinity ligands cibacron blue and procion red free in solution on the partitioning of G6PD in the two-phase micellar systems studied (TX-114 and $\mathrm{C}_{10} \mathrm{E}_{4}$ ) is that those molecules might be poorly accessible to bind the enzyme. Due to the chemical structures of the dyes and to their amphiphilic character, they probably interact with nonionic surfactant molecules and aggregate within the micelles between the polar ethylene oxide moieties and the hydrophobic tails, difficulting the formation of the enzyme-ligand complex.

In the absence of affinity interactions, it has been shown previously that the partitioning of hydrophilic proteins, such as G6PD, can be modeled adequately in terms of steric considerations. ${ }^{8,10}$ Specifically, since hydrophilic proteins tend to remain in the aqueous domain outside the micelles when placed in two-phase aqueous micellar systems, their partitioning behavior is a function of the difference in free volume between the two coexisting micellar phases. In this case, larger biomolecules partition more extremely into the micelle-poor phase where they experience less repulsive excluded-volume $(E V)$ interactions with the micelles. ${ }^{3,12,33}$

Lam et al. ${ }^{19}$ studied green fluorescent protein (GFP) partitioning using affinity-tagged GFP fused to a family 9 carbohydrate-binding module (CBM9-GFP) in two-phase aqueous micellar system composed of the nonionic surfactant $n$-decyl $\beta$-D-glucopyranoside $\left(\mathrm{C}_{10} \mathrm{G}_{1}\right)$. These authors showed that the fusion protein CBM9-GFP was extracted preferentially into the micelle-rich phase, with more than a sixfold increase in the protein partition coefficient, due to the specific affinity interactions between the CBM9 domains and the $\mathrm{C}_{10} \mathrm{G}_{1}$ surfactants. The GFP, unlike CBM9-GFP, partitioned preferentially into the micelle-poor phase $(K \mathrm{p}<1)$, in line with the expectation that in the absence of other interactions, the excludedvolume interactions between the protein and the micelles will tend to drive the protein into the micelle-poor phase based on size..$^{8,10,34}$

The protein CBM9-GFP, when compared to the enzyme G6PD is relatively smaller $\left(R_{p, G 6 P D}=68 \AA, R_{p, C B M 9-G F P} \sim 26-49 \AA\right),{ }^{35,36}$ and therefore it should experience a smaller excluded-volume effect than G6PD. In addition, the CBM9-GFP protein interacts with the glucosidic head group of the micelle forming surfactant, whereas in the present study, G6PD interacts with the free ligand (cibacron blue or procion red) that may not be fully accessible for binding the enzyme due to its preferential interaction with the surfactant.

In another study, Kroner et al. ${ }^{29}$ observed that the partition coefficient of glucose-6-phosphate dehydrogenase in aqueous twophase systems can be raised from values lower than 1 to higher 
than 20 by the addition of cibacron blue or procion red covalently bound to polyethylene glycol in a suitable system. Here, again, the ligands were covalently bound to the phase forming polymer, in contrast to the present study with free cibacron blue. Also, these authors studied PEG-Dextran systems that, when compared to micellar systems, present smaller excluded-volume effect since when phase separation takes place it results in a PEG-rich phase and a Dextran-rich phase.

Saitoh et $a l .{ }^{37}$ studied protein (BSA, alcohol dehydrogenase, lysozyme and ovalbumin) separation utilizing cibacron blue 3GAconjugated Triton X-100, (cibacron blue-Triton) combined with Triton X-100-coated polystyrene for providing specific interaction with certain proteins. According to the authors, the extent of BSA and lysozyme recovery increased with increasing cibacron blueTriton fraction. In contrast, ovalbumin, having no specific interaction to cibacron blue, was hardly collected by cibacron blue-Triton admicelles. Although lysozyme has no specific binding site for $\mathrm{NAD}^{+}$, its strong interactions with cibacron blue has been utilized for dye affinity-based purification. ${ }^{38,39}$ The strong interaction may be explained by electrostatic forces between negatively charged cibacron blue-Triton and positively charged lysozyme. ${ }^{40}$ Surprisingly, the recovery of the $\mathrm{NAD}^{+}$dependent enzyme alcohol dehydrogenase was lower in the presence of the cibacron blueTriton affinity admicelle when compared to uncovered polystyrene resin. This finding suggests that this kind of affinity interactions between $\mathrm{NAD}(\mathrm{P})^{+}$dependent enzymes and triazine dyes might not be strong enough in some cases. Similarly, in the present work, the affinity interaction was not strong enough to attract the G6PD to the micelle-rich phase and overcome the excluded-volume effect. In addition the G6PD and dyes molecules are all negatively charged in the systems conditions and, consequently, the electrostatic forces among cibacron blue, procion red and G6PD are predominantly repulsive, despite the main affinity interaction.

Not only the G6PD partitioning profile was altered by the presence of the ligands, but also the behavior of the ligand changed in the presence of the enzyme. Table 2 presents the results of the ligands partition coefficients at $19.5^{\circ} \mathrm{C}$ in the presence of G6PD and, comparing to the results in the absence of enzyme (Table 1), lower values of $K_{\text {Ligand }}$ were observed. In this sense, although an increase in the partition coefficient of G6PD is observed in the presence of affinity ligands (Table 2), a decrease in the partition coefficient of the ligands might also takes place due to the binding to G6PD, which partitions preferentially to the diluted, micellepoor phase. Considering the size of G6PD and the power of excluded-volume interactions, it is more likely to the partitioning of the ligand to be influenced by the presence of the enzyme than the opposite.

With the purpose of minimizing the excluded-volume effect on the partition coefficient and possibly increase G6PD partitioning to the micelle-rich phase, new experiments were carried out in $\mathrm{C}_{10} \mathrm{E}_{4}$ system at conditions corresponding to a smaller excluded-volume effect. For these experiments we employed a temperature of $19.1^{\circ} \mathrm{C}$, providing $\left(\phi_{c}-\phi_{d}\right)=0.032$. The concentration of $\mathrm{C}_{10} \mathrm{E}_{4}$ was $1.5 \%$ $(\mathrm{w} / \mathrm{w})$ and the concentrations of cibacron blue and procion red were the same as previous $(0.005 \mathrm{mg} / \mathrm{g})$. Table 2 presents the $K_{\mathrm{G} 6 \mathrm{PD}}$ values obtained at these conditions. As can be seen, a small but statistically significant increment in $K_{\mathrm{G} 6 \mathrm{PD}}$ was observed in the presence of affinity ligands, with $K_{\mathrm{G} 6 \mathrm{PD}}$ going from 0.63 in the absence of ligand to 0.72 in the presence of cibacron blue or procion red.

One should note that the partition coefficient of the ligands also varied with the decrease of the difference in surfactant concentration in the phases of the system, $\left(\phi_{\mathrm{c}}-\phi_{\mathrm{d}}\right)$. The $K_{\text {Ligand }}$ decreases because partition of the ligand is associated to micellar formation and, therefore, it is directly proportional to $\left(\phi_{\mathrm{c}}-\phi_{\mathrm{d}}\right)$. In other words, increasing the temperature leads to higher $\left(\phi_{c}-\phi_{d}\right)$ values and, consequently, increases partition of the ligands to the micelle-rich phase. Therefore, as expected, the partition coefficients of cibacron blue and procion red obtained in the $\mathrm{C}_{10} \mathrm{E}_{4}$ system with $\left(\phi_{c}-\phi_{d}\right)=0.032$ were lower than the ones obtained with $\left(\phi_{c}-\phi_{d}\right)=$ 0.050 (Table 2). Nevertheless, they were still higher than 1 ( $K_{\text {cibacron }}$ lue $=3.7$ and $K_{\text {procion red }}=3.8$ ).

One could envision a preferential partitioning of G6PD to the micellar phase of a system formed by covalently bound cibacron blue and Triton X-114. In this sense, what was observed by Lam et al. ${ }^{19}$ when studying the protein GFP could also be observed for G6PD in a system composed by an affinity-type surfactant. In fact, Garg et al. ${ }^{18}$ synthesized such Triton X-114-cibacron blue affinity surfactant. By mixing the affinity surfactant with pure Triton $\mathrm{X}$ 114 , polyethyleneglycol, and hydroxypropyl-starch, the authors observed the formation of a three-phase micellar system with a surfactant-rich middle phase containing both the Triton X-114 and the affinity surfactant. They employed this system to purify the enzyme lactate dehydrogenase, which partitioned preferentially to the surfactant-rich phase due to affinity interactions. However, the following recovery of the enzyme was done by harvesting the surfactant-rich phase and subjecting it to temperature-induced phase separation, whereby the surfactants concentrated in one phase and the enzyme was recovered in the water-rich phase (or micelle-poor phase). Again, even when employing an affinity surfactant, the excluded-volume seems to play the main role in large proteins partitioning in aqueous two-phase micellar systems, and the same behavior should probably be observed for G6PD.

\section{CONCLUSIONS}

The aim of this work was to evaluate the effect of affinity interactions on the partitioning of the enzyme G6PD in two-phase aqueous micellar systems. We studied two ligands, cibacron blue and procion red, and compared G6PD partitioning in the presence and absence of these ligands in nonionic micellar systems composed by the surfactants Triton X-114 and $\mathrm{C}_{10} \mathrm{E}_{4}$. Our results indicate that, in spite of the clear presence of affinity interactions, those were not strong enough to significantly overcome the excluded-volume effect and drive the enzyme preferentially to the micelle-rich phase containing the affinity ligands. Therefore, we have not obtained partition coefficient values higher than one at any conditions studied. Discussion of results earlier presented by other authors also suggests that excluded-volume interactions strongly influence the partitioning of large proteins in any aqueous two-phase system, even when employing affinity-type surfactants. Nevertheless, the use of an aqueous two-phase system composed of a polymer-rich phase and a micellar-rich phase containing the affinity ligand could result in better partitioning of G6PD to the micellar phase, since the exclusion by the volume would not be as strong as in the absence of the polymer.

\section{REFERENCES}

1. Wilchek, M. M. T.; React. Funct. Polym. 1999, 41, 263.

2. Hinze, W. L.; Pramauro, E.; Crit. Rev. Anal. Chem. 1993, 24, 133.

3. Liu, C. L.; Nikas, Y. J.; Blankschtein, D.; Biotechnol. Bioeng. 1996, 52, 185.

4. Liu, C. L.; Kamei, D. T.; King, J. A.; Wang, D. I. C.; Blankschtein, D.; J Chromatogr., B: Anal. Technol. Biomed. Life Sci. 1998, 711, 127.

5. Ramelmeier, R. A.; Terstappen, G. C.; Kula, M. R.; Bioseparation 1991, 2,315 .

6. Alred, P. A.; Kozlowski, A.; Harris, J. M.; Tjerneld, F.; J Chromatogr., A 1994, 659, 289. 
7. Bordier, C.; J. Biol. Chem. 1981, 256, 1604.

8. Nikas, Y. J.; Liu, C. L.; Srivastava, T.; Abbott, N. L.; Blankschtein, D.; Macromolecules 1992, 25, 4794.

9. Rangel-Yagui, C. O.; Pessoa-Jr., A.; Blankschtein, D.; Braz. J Chem. Eng. 2004, 21, 531.

10. Lue, L.; Blankschtein, D.; Ind. Eng. Chem. Res. 1996, 35, 3032

11. Kamei, D. T.; King, J. A.; Wang, D. I. C.; Blankschtein, D.; Biotechnol Bioeng. 2002, 80, 233.

12. Rangel-Yagui, C. O.; Lam, H.; Kamei, D. T.; Wang, D. I. C.; Pessoa-Jr., A.; Blankschtein, D.; Biotechnol. Bioeng. 2003, 82, 445.

13. Flanagan, S. D.; Barondes, S. H.; J. Biol. Chem. 1975, 250, 1484.

14. Saitoh, T.; Hinze, W. L.; Talanta 1995, 42, 119.

15. Lam, H.; Kavoosi, M.; Haynes, C. A.; Wang, D. I. C.; Blankschtein, D.; Biotechnol. Bioeng. 2005, 89, 381.

16. Sivars, U.; Tjerneld, F.; Biochim. Biophys. Acta 2000, 1474, 133.

17. Wuenschell, G. E.; Naranjo, E.; Arnold, F. H.; Bioproc. Eng. 1990, 5, 199

18. Garg, N.; Galaev, I. Y.; Mattiasson, B.; Biotechnol. Appl. Biochem. 1994, 20, 199.

19. Fernandes, S.; Hatti-Kaul, R.; Mattiasson, B.; Biotechnol. Bioeng. 2002, 79, 472.

20. Mazzola, P. G.; Lam, H.; Kavoosi, M.; Haynes, C. A.; Pessoa-Jr., A.; Penna, T. C. V.; Wang, D. I. C.; Blankschtein, D.; Biotechnol. Bioeng. 2006, 93, 998.

21. Champluvier, B.; Kula, M. R.; Biotechnol. Bioeng. 1992, 40, 33.

22. Chang, Y. K.; MCcreath, G. E.; Chase, H. A.; Biotechnol. Bioeng. 1995, $48,355$.

23. Bassi, A. S.; Tang, D. Q.; Bergougnou, M. A.; Anal. Biochem. 1999, 268, 223.

24. Lojudice, F. H.; Silva, D. P.; Zanchin, N. I. T.; Oliveira, C. C.; Pessoa-Jr., A.; Appl. Biochem. Biotechnol. 2001, 91/93, 161.
25. Bergmeyer, H. U.; Methods of enzymatic analysis: samples, reagents, assessment of results, $3^{\text {rd }}$ ed.; Verlag Chemie: Weinheim, 1983, vol. 2, p. 190.

26. Albertsson, P. A.; Partition of cell particles and macromolecules, $3^{\text {rd }}$ ed.; Wiley-Interscience: New York, 1986

27. Blankschtein, D.; Thurston, G. M.; Benedek, G. B.; J. Chem. Phys. 1986, 85,7268 .

28. Kopperschläger, G.; Methods in Enzymology 1994, 228, 121

29. Kroner, K. H.; Cordes, A.; Schelper, A.; Morr, M.; Büchmann, A. F.; Kula, M. R. Em Affinity chromatography and related techniques: theoretical aspects/industrial and biomedical applications: proceedings of the 4th International Symposium; Gribnau, T. C. J.; Visser, J.; Nivard, R. J. F., eds.; Veldhoven, the Netherlands, 1981.

30. Johansson, G.; Andersson, M.; Akerlund, H. E.; J. Chromatogr. 1984, 298, 483.

31. Rudge, J.; Bickerstaff, G. F.; Enzyme Microb. Technol. 1986, 8, 120.

32. Raya-Tonetti, G.; Perotti, N. I.; Biotechnol. Appl. Biochem. 1999, $29,151$.

33. Kamei, D. T.; King, J. A.; Wang, D. I. C.; Blankschtein, D.; Biotechnol. Bioeng. 2002, 78, 203.

34. Liu, C. L.; Nikas, Y. J.; Blankschtein, D.; AlChE J. 1995, 41, 991.

35. Hink, M. A.; Griep, R. A.; Borst, J. W.; van Hoek, A.; Eppink, M. H. M.; Schots, A.; Visser, A. J. W. G.; J Biol. Chem. 2000, 275, 17556.

36. Rowland, P.; Basak, A. K.; Gover, S.; Levy, H. R.; Adams, M. J.; Structure 1994, 2, 1073.

37. Saitoh, T.; Makino, D.; Hiraide, M.; J. Chromatogr., A 2004, 1057, 101

38. Horstmann, B.; Kenny, C. N.; J. Chromatogr., A 1986, 361, 179.

39. Chen, C. H.; Lee, W. C.; J. Chromatogr., A 2001, 921, 31.

40. Barroug, A.; Lemaitre, J.; Rouxhet, P. G.; Colloids Surf. 1989, 37, 339. 